\title{
Enigma Plays Roles in Survival of Thyroid Carcinoma Cells through PI3K/AKT Signaling and Survivin
}

\author{
YOON JUNG KIM*, HYO-JEONG HWANG*, JUN GOO KANG, CHUL SIK KIM, \\ SUNG-HEE IHM, MOON GI CHOI and SEONG JIN LEE \\ Division of Endocrinology and Metabolism, Department of Internal Medicine, \\ College of Medicine, Hallym University, Chuncheon, Republic of Korea
}

\begin{abstract}
Background/Aim: The aim of the present study was to assess the role of enigma protein in survival of thyroid carcinoma cells. Materials and Methods: BCPAP and 8505C human thyroid carcinoma cells were used. Cell viability using CCK-8 assay, the percentage of dead cells using trypan blue assay, cytotoxic activity using cytotoxicity assay, cell growth rate and cell migration using woundhealing assay were performed. Results: In enigma siRNAtransfected cells, cell viability, and the protein levels of AKT and survivin decreased. The percentage of dead cells, cytotoxic activity and cleaved poly (ADP-ribose) polymerase $(P A R P)$ protein levels increased. After transfection of $p 110 \alpha$ plasmid, the alterations in cell viability, the percentage of dead cells, cytotoxic activity, and protein levels of AKT, survivin and cleaved PARP were abrogated. Cell growth rate and cell migration were reduced with reduction of matrix metalloproteinase-2 (MMP-2) and matrix metalloproteinase9 (MMP-9) protein levels, as well as increased p53 and p21 protein levels. Conclusion: Enigma affects cell survival through modulation of phosphatidylinositol-3 kinase/AKT signaling and survivin, and regulates cell proliferation and migration via involvement of MMP-2, MMP-9, p53 and p21 in thyroid carcinoma cells.
\end{abstract}

Well-differentiated thyroid carcinoma (WDTC), including papillary thyroid carcinoma (PTC) and follicular thyroid carcinoma (FTC), has an excellent outcome, whereas WDTC

\footnotetext{
*These Authors contributed equally to this study.

Correspondence to: Seong Jin Lee, Division of Endocrinology and Metabolism, Department of Internal Medicine, College of Medicine, Hallym University, Chuncheon 200-704, Republic of Korea. Tel: +82 313803700, Fax: +82 313833768, e-mail: leesj@hallym.ac.kr
}

Key Words: Thyroid carcinoma, PDZ-LIM family, enigma, AKT, survivin. in approximately $70 \%$ of patients with distant metastasis is refractory to radioactive iodine therapy $(1,2)$. Meanwhile, undifferentiated thyroid carcinoma, predominantly anaplastic thyroid carcinoma (ATC), shows highly aggressive behavior characterized as extrathyroidal invasion and distant metastasis, thereby presenting an unfavorable prognosis $(1,2)$. Since radioactive iodine therapy-refractory WDTC and undifferentiated thyroid carcinoma can be resistant to conventional treatments, new therapeutic target molecules to improve the outcome of patients are under investigation $(1,2)$.

The PDZ-LIM family is composed of proteins with multiple functional domains, and the proteins share an $\mathrm{N}$ terminal PDZ domain combined with at least one $C$-terminal LIM domain (3). The PDZ domain attaches the protein to the cell membrane, and the LIM domain communicates with protein kinases which are responsible for insulin and mitogenic signaling such as rearranged during transfection (RET)/PTC2 (RET/PTC2) (4-8). Under physiological conditions, the PDZ-LIM family proteins modulate various steps during development and homeostasis, and maintain cytoskeletons and cell adhesion through complementary interaction with integrin $(3,9,10)$. In contrast, the PDZ-LIM family protein Epstein-Barr virus latent membrane protein-1 (LMP-1) suppresses cell death by regulating phosphatidylinositol-3 kinase (PI3K)/AKT signaling and the chemoresistance factor survivin in nasal natural killer/T-cell lymphoma in vitro and in vivo models (11).

Enigma (also named PDLIM7 and LMP-4) belongs to the PDZ-LIM family, and has a PDZ and three LIM domains (68 ). Functionally, enigma serves as a scaffold protein via interconnection with cytoskeleton network, and acts as an adaptor protein through stabilization of cell membrane and signaling machinery (12). With respect to the role of enigma in organ development, enigma promotes heart and skeletal muscle organization, and enhances bone morphogenetic factor-mediated osteogenesis, thereby being involved in direct and endochondral bone formation $(3,13)$. In regard to the role of enigma in tumorigenesis, enigma facilitates cell survival and chemoresistance by inhibiting p53-mediated 

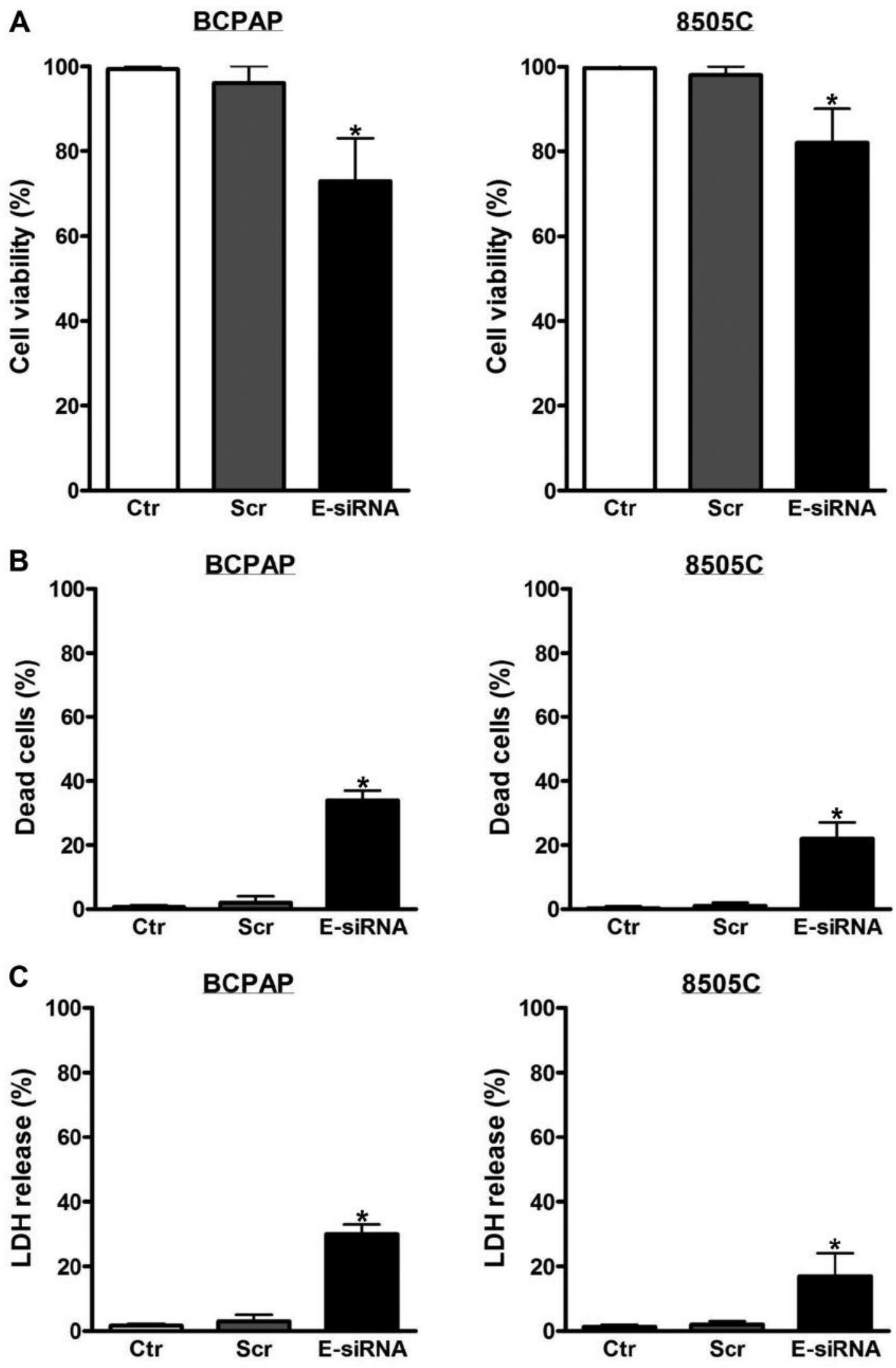

Figure 1. Continued 


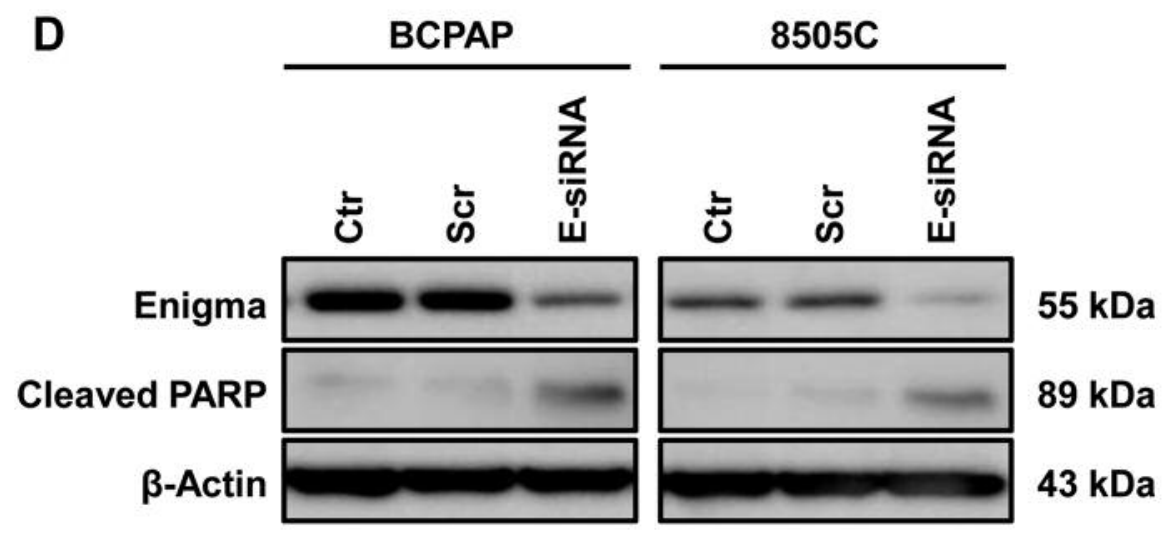

Figure 1. The role of enigma in survival of thyroid carcinoma cells. BCPAP and 8505C cells were transfected with enigma siRNA (E-siRNA) for $48 \mathrm{~h}$, and then cell viability using CCK-8 assay (A), the percentage of dead cells using trypan blue assay (B), cytotoxic activity using cytotoxicity assay $(C)$, and the protein levels of enigma and cleaved poly (ADP-ribose) polymerase (PARP) $(D)$, were measured. All experiments were performed in triplicate. The blots are representative of independent experiments. Data are expressed as mean \pm S.E. ${ }^{*} p<0.05$ vs. control (Ctr). LDH: Lactate dehydrogenase; Scr: scramble RNA.

death of human hepatoma and colon cancer cells (14). Moreover, enigma blocks Casitas B-lineage lymphoma-c (CBL-c)-mediated degradation of oncogenic protein named as RET multiple endocrine neoplasia type 2A (RETMEN2A) (15). In patients with breast cancer with activated RET, overexpression of enigma correlates with a poor survival outcome (15). In thyroid cancer, it was reported that high expression of enigma was exhibited in malignant tissues, and related to advanced pathological staging (16). However, the role of enigma in survival of thyroid carcinoma cells has not been elucidated.

The aim of the present study was to evaluate the role of enigma in survival of thyroid carcinoma cells. We for the first time demonstrate that enigma has a pivotal role in cell survival via modulation of PI3K/AKT signaling and survivin in thyroid carcinoma cells. Furthermore, enigma affects cell proliferation and migration in thyroid carcinoma cells.

\section{Materials and Methods}

Materials. RPMI1640, Dulbecco's modified Eagle's medium (DMEM), fetal bovine serum (FBS), L-glutamine and streptomycin/penicillin were purchased from Life Technologies (Carlsbad, CA, USA). Primary antibodies against enigma, and total and phospho-AKT (Ser473) were obtained from Santa Cruz Biotechnology (Santa Cruz, CA, USA), and those against $\beta$-actin were obtained from Sigma-Aldrich (St. Louis, MO, USA). Primary antibodies against cleaved poly (ADP-ribose) polymerase (PARP), survivin, matrix metalloproteinase-2 (MMP-2), matrix metalloproteinase-9 (MMP-9), p53 and p21 were purchased from Cell Signaling Biotechnology (Danvers, MA, USA). All other reagents were obtained from Sigma-Aldrich unless otherwise stated. Cell culture. For experiments, BCPAP human PTC cells and 8505C human ATC cells were used since these are widely popular in vitro models of thyroid carcinoma. Both cells were purchased from Deutsche Sammlung von Mikroorganismenund Zellkulturen (DSMZ GmbH, Braunschweig, Germany). BCPAP cells were grown in RPMI1640 supplemented with $2 \mathrm{mM}$ L-glutamine, $10 \%$ heat-inactivated FBS and $1 \%$ streptomycin/penicillin. $8505 \mathrm{C}$ cells were grown in DMEM supplemented with $10 \%$ heat-inactivated FBS and $1 \%$ streptomycin/ penicillin. Cells received fresh medium at regular intervals. Treatments and experiments were performed using cells that were $70 \%$ confluent.

Transfection of small interfering RNA (siRNA) and plasmid. An enigma siRNA from Santa Cruz Biotechnology and a p110 $\alpha$ plasmid from Addgene (Cambridge, MA, USA) were purchased. Cells were transfected with siRNA and plasmid using Lipofectamine 3000 Reagent (Life Technologies) according to the manufacturer's protocol. Transfection efficiency was tested by western blotting.

CCK-8 assay. After transfection of enigma siRNA and p $110 \alpha$ plasmid, viability of BCPAP and $8505 \mathrm{C}$ cells was assessed using CCK- 8 assay. Cell viability was determined by the CCK- 8 Assay Kit (Dojindo laboratories, Kumamoto, Japan). Cells $\left(5 \times 10^{3} / 100 \mu \mathrm{l}\right)$ in each well on 96-well plates were incubated overnight. Absorbance was measured at $450 \mathrm{~nm}$ using a spectrophotometer (Molecular Devices, Palo Alto, CA, USA). All experiments were performed in triplicate.

Trypan blue assay. The percentage of dead cells after transfection of enigma siRNA and p110 $\alpha$ plasmid in BCPAP and $8505 \mathrm{C}$ cells was measured using trypan blue assay. Cells $\left(5 \times 10^{4} / 500 \mu \mathrm{l}\right)$ in each well on 12-well plates were incubated, and mixed with trypan blue dye at $37^{\circ} \mathrm{C}$. Stained cells were counted using hemocytometer. All experiments were performed in triplicate.

Cytotoxicity assay. In BCPAP and 8505C cells, cytotoxic activity under transfection of enigma siRNA and p110 $\alpha$ plasmid was assessed using cytotoxicity assay. Cytotoxic activity was measured by the lactate dehydrogenase (LDH) Cytotoxicity Assay Kit (BioVision, Linda, CA, USA). Cells $\left(5 \times 10^{3} / 100 \mu \mathrm{l}\right)$ in each well on 
96-well plates were incubated, and centrifuged at $250 \times g$ for $10 \mathrm{~min}$. Supernatant of $100 \mu \mathrm{l}$ was transferred in clear 96-well plates. After addition of reaction mixture $(2.5 \mu \mathrm{l}$ Catalyst solution in $112.5 \mu \mathrm{l}$ Dye solution), cells were incubated for $30 \mathrm{~min}$ at room temperature. Absorbance was measured at $495 \mathrm{~nm}$ using a spectrophotometer. All experiments were performed in triplicate.

Wound-healing assay. Cell migration after transfection of enigma siRNA in BCPAP and $8505 \mathrm{C}$ cells was assessed using woundhealing assay. Cell migration was measured by the CytoSelect ${ }^{\mathrm{TM}} 24$ Well Wound Healing Assay Kit (Cell Biolabs, San Diego, CA, USA). Cells $\left(1 \times 10^{5 / 500 \mu l)}\right.$ in plates were incubated overnight, and then a wound $(0.9 \mathrm{~mm})$ was created in the cell monolayer. The wound closure was monitored by light microscopy, and the cell migration rate was calculated according to the following equation: cell migration=[length of cell migration $(\mathrm{nm}) /$ migration time $(\mathrm{h})]$. All experiments were performed in triplicate.

Western blotting. The total protein was extracted by RIPA buffer (Sigma-Aldrich) containing $1 \times$ protease inhibitor cocktail and $1 \times$ phophatase inhibitor cocktail set V (Calbiochem, La Jolla, CA, USA). Western blotting was performed using the specific primary antibodies detailed above and horseradish peroxidase-conjugated anti-rabbit and anti-mouse secondary antibodies. Bands were detected using ECL Plus Western Blotting Detection System (Thermo Fisher Scientific, Rockford, IL, USA). The protein levels were quantified by densitometry using ImageJ software (NIH, Bethesda, Maryland, USA), and normalized to $\beta$-actin levels. All experiments were performed in triplicate.

Statistical analysis. All data are expressed as mean \pm standard error (S.E). Data were analyzed by unpaired Student's $t$-test or ANOVA as appropriate. A $p$-value less than 0.05 was considered to be statistically significant. All analyses were performed using SPSS program version 23.0 (IBM Corp., Armonk, NY, USA).

\section{Results}

Silencing of enigma induces death of thyroid carcinoma cells. To evaluate the role of enigma in survival of thyroid carcinoma cells, BCPAP and 8505C cells were transfected with enigma siRNA for $48 \mathrm{~h}$. After transfection, cell viability was significantly diminished (Figure 1A), and the percentage of dead cells (Figure 1B) and cytotoxic activity (Figure 1C) were significantly enhanced. Moreover, enigma protein levels were significantly diminished, and cleaved PARP protein levels were significantly enhanced (Figure 1D). Taken together, these results demonstrate that repression of enigma causes death of thyroid carcinoma cells.

Enigma modulates PI3K/AKT signaling and survivin in thyroid carcinoma cells. PI3K/AKT signaling plays an essential role in survival, growth and differentiation of thyroid carcinoma cells $(17,18)$. Survivin, a chemoresistance factor, participates in survival of thyroid carcinoma cells (19). In the present study, to investigate the influence of enigma on PI3K/AKT signaling and survivin, cells were transfected with enigma siRNA for $48 \mathrm{~h}$, after which the protein levels of total and phospho-AKT, and survivin were measured. As a result of transfection, the protein levels of total and phospho-AKT, and survivin were significantly reduced (Figure $2 \mathrm{~A}$ and $\mathrm{B}$ ), indicating that suppression of enigma inhibits PI3K/AKT signaling and survivin in thyroid carcinoma cells.

Stimulation of PI3K/AKT signaling mitigates cell death in conjunction with increment of survivin in enigma-inactivated thyroid carcinoma cells. In the present study, underexpression of enigma impeded PI3K/AKT signaling in thyroid carcinoma cells, and thus the involvement of PI3K/AKT signaling in survival of cells under transfection with enigma siRNA was explored. For augmentation of PI3K/AKT signaling, cells were transfected with $\mathrm{p} 110 \alpha$ plasmid prior to transfection of enigma siRNA for $48 \mathrm{~h}$. Compared with enigma siRNAtransfected cells, in cells transfected with both p110 $\alpha$ plasmidand enigma siRNA, the protein levels of total and phosphoAKT, and survivin, and cell viability significantly increased, while the cleaved PARP protein level significantly decreased (Figure 3A-C). Correspondingly, the percentage of dead cells and cytotoxic activity significantly decreased (Figure 3D and E). In summary, these results reveal that activation of PI3K/AKT signaling curtails cell death with retrieval of survivin in enigma-deprived thyroid carcinoma cells.

Knockdown of enigma ameliorates proliferation and migration of thyroid carcinoma cells. Firstly, in order to evaluate the relevance of enigma to cell proliferation, cells were transfected with enigma siRNA and the cell growth rate was measured after 12, 24, 36 and $48 \mathrm{~h}$. The cell growth rate was significantly diminished at 24, 36 and $48 \mathrm{~h}$ after transfection (Figure 4A).

Next, in order to investigate the relation of enigma to cell migration, cells were transfected with enigma siRNA for $48 \mathrm{~h}$ and cell migration was assessed using wound-healing assay. After transfection, cell migration was significantly diminished (Figure 4B and C). The protein levels of MMP2, MMP-9, p53 and p21 were also measured (Figure 4D) and found to be significantly diminished, while those of p53 and p21 were significantly enhanced (Figure 4E).

Collectively, these results show that repression of enigma curbs cell proliferation and migration with concomitant alteration in MMP-2, MMP-9, p53 and p21 in thyroid carcinoma cells.

\section{Discussion}

To our knowledge, this study is the first to demonstrate that inhibition of enigma induces cell death via mediation of PI3K/AKT signaling and survivin in thyroid carcinoma cells. Moreover, repression of enigma reduces cell proliferation 
A

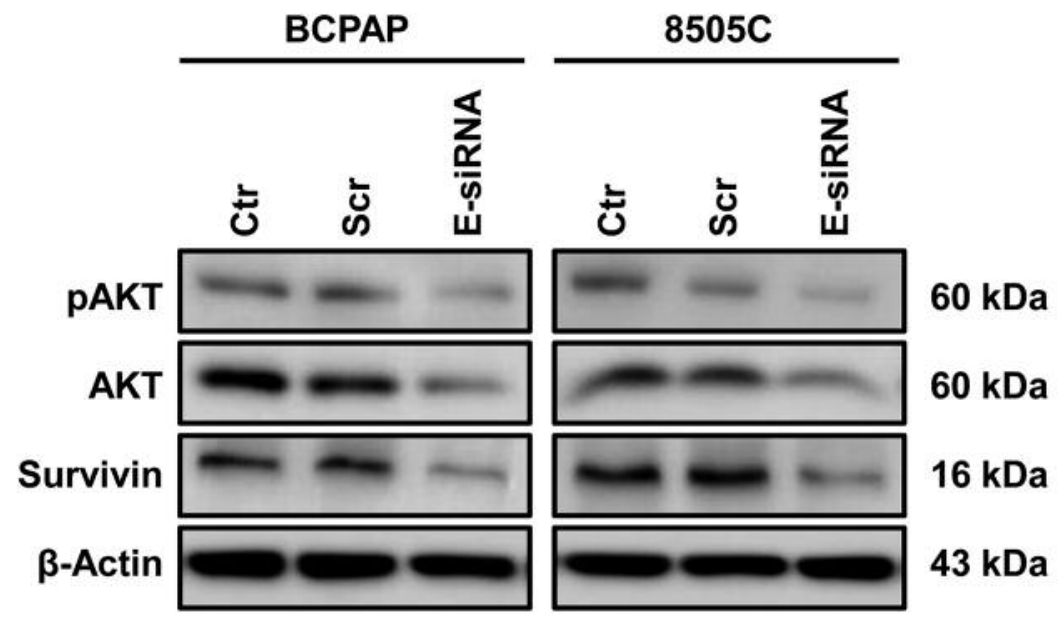

B
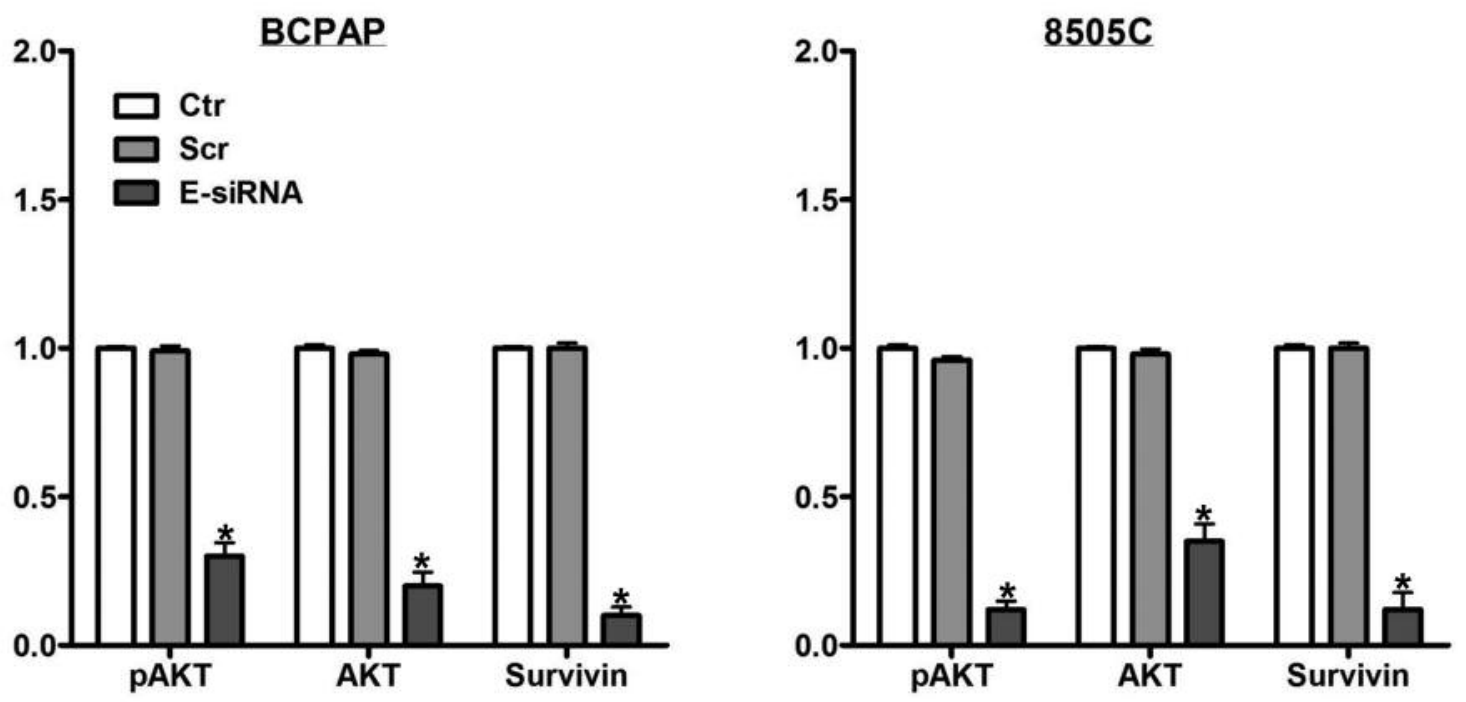

Figure 2. The influence of enigma on phosphatidylinositol-3 kinase (PI3K)/AKT signaling and survivin in thyroid carcinoma cells. BCPAP and $8505 \mathrm{C}$ cells were transfected with enigma siRNA (E-siRNA) for $48 \mathrm{~h}$, after which the protein levels of total and phospho-AKT, and survivin were measured $(A)$, and quantified by densitometry $(B)$, and normalized to $\beta$-actin levels. All experiments were performed in triplicate. The blots are representative of independent experiments. Data are expressed as mean \pm S.E. ${ }^{*} p<0.05$ vs. control (Ctr). Scr: Scramble RNA.

and migration through modulation of MMP-2, MMP-9, p53 and $\mathrm{p} 21$ in thyroid carcinoma cells.

Overexpression of enigma is associated with prolonged survival of human hepatoma and colon cancer cells, and with poor prognosis in patients with RET-activated breast cancer $(14,15)$. In thyroid cancer, it was reported that enigma was highly expressed in malignant compared with benign tissues, and overexpression of enigma was positively correlated with pathological staging (16). However, the direct role of enigma in survival of thyroid carcinoma cells remains enigmatic. In the present study, suppression of enigma reduced cell viability, and increased the percentage of dead cells, cytotoxic activity and cleaved PARP protein level, reflecting that enigma plays a fundamental role in survival of thyroid carcinoma cells. With respect to the position for enigma as a new therapeutic target in thyroid cancer, further studies are necessary to substantiate whether these phenomena are reproducible in in vivo models.

PI3K/AKT signaling takes part in various intracellular processes essential for survival in normal and cancer cells (20). In thyroid cancer, aberrant activation of PI3K/AKT signaling was shown to be involved in triggering of carcinogenesis $(17,18)$. In this regard, we reported that PI3K/AKT signaling plays critical roles in survival of 
A

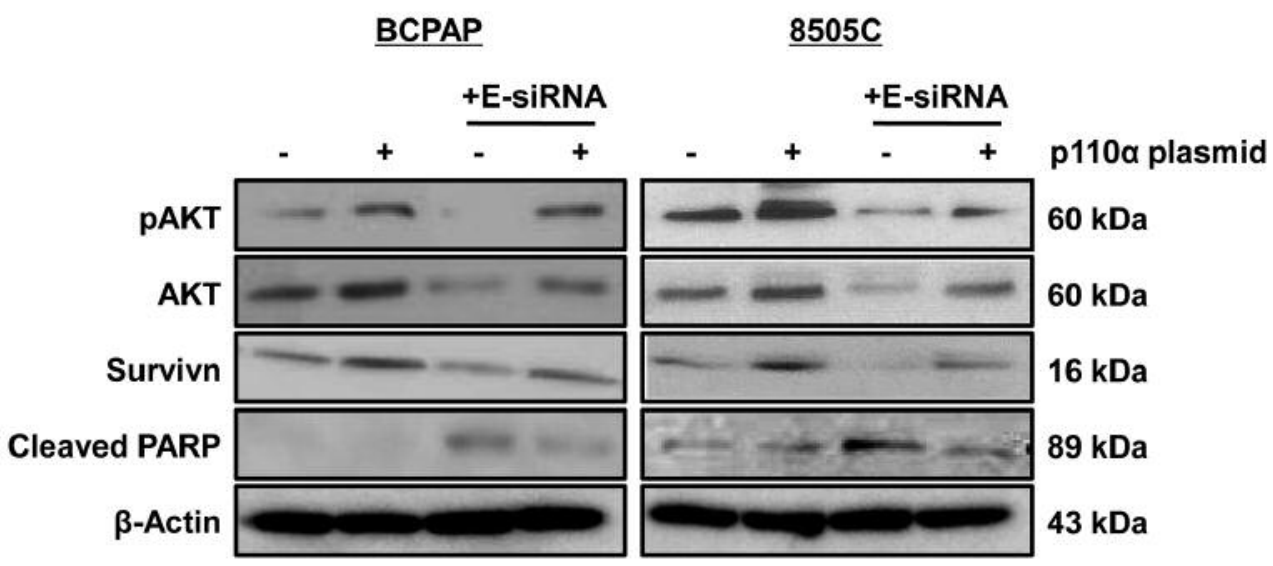

B
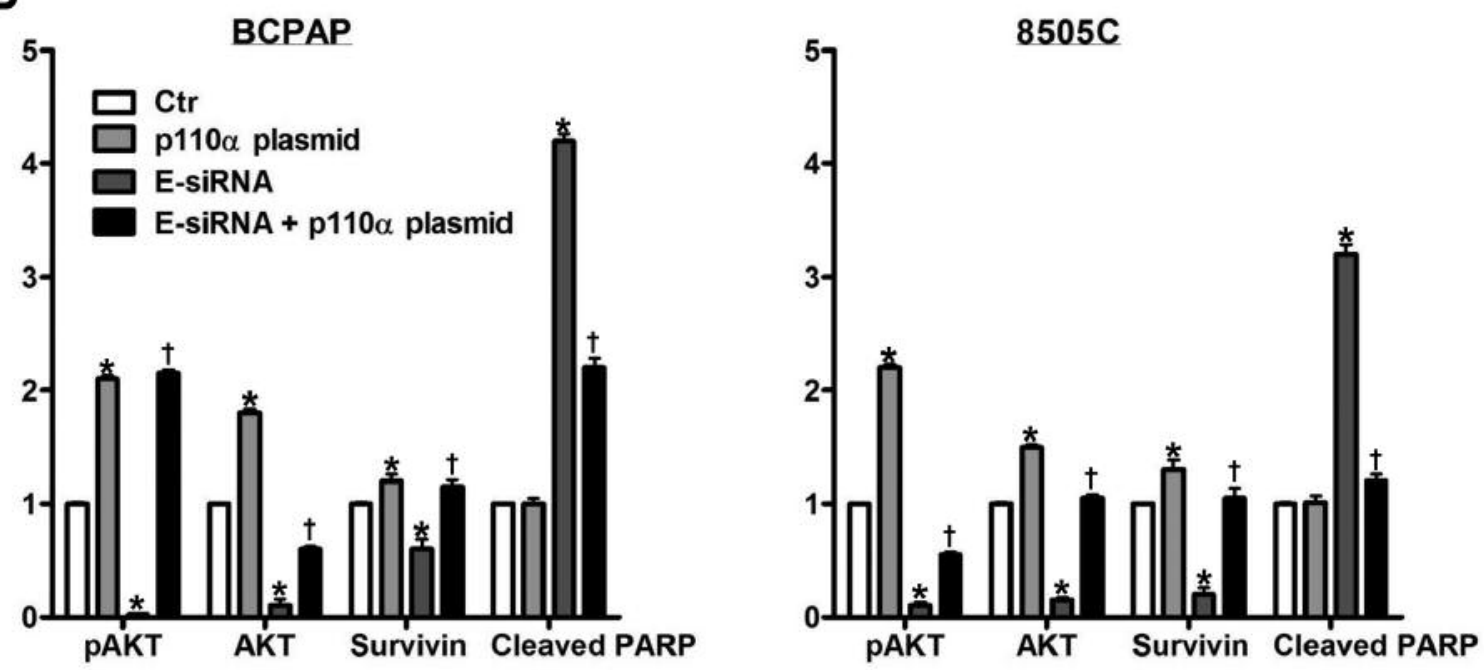

C

BCPAP

$8505 C$
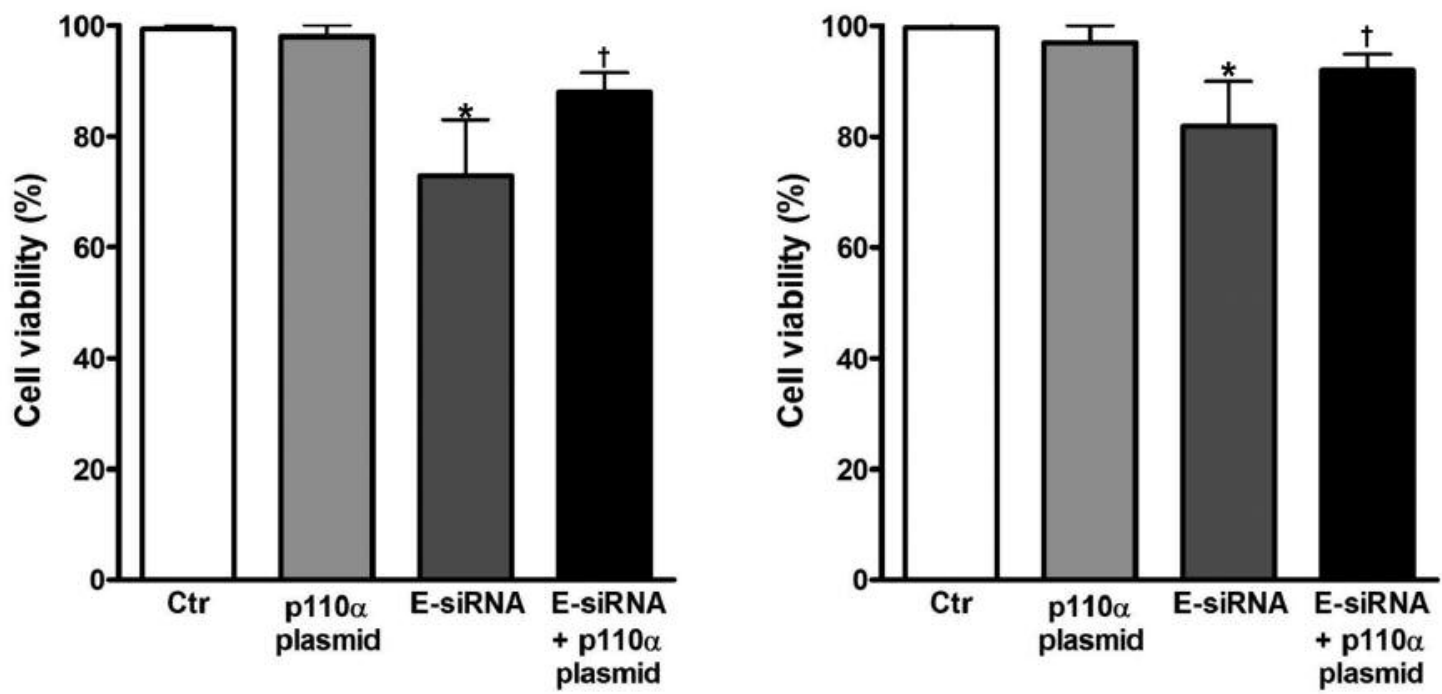

Figure 3. Continued 

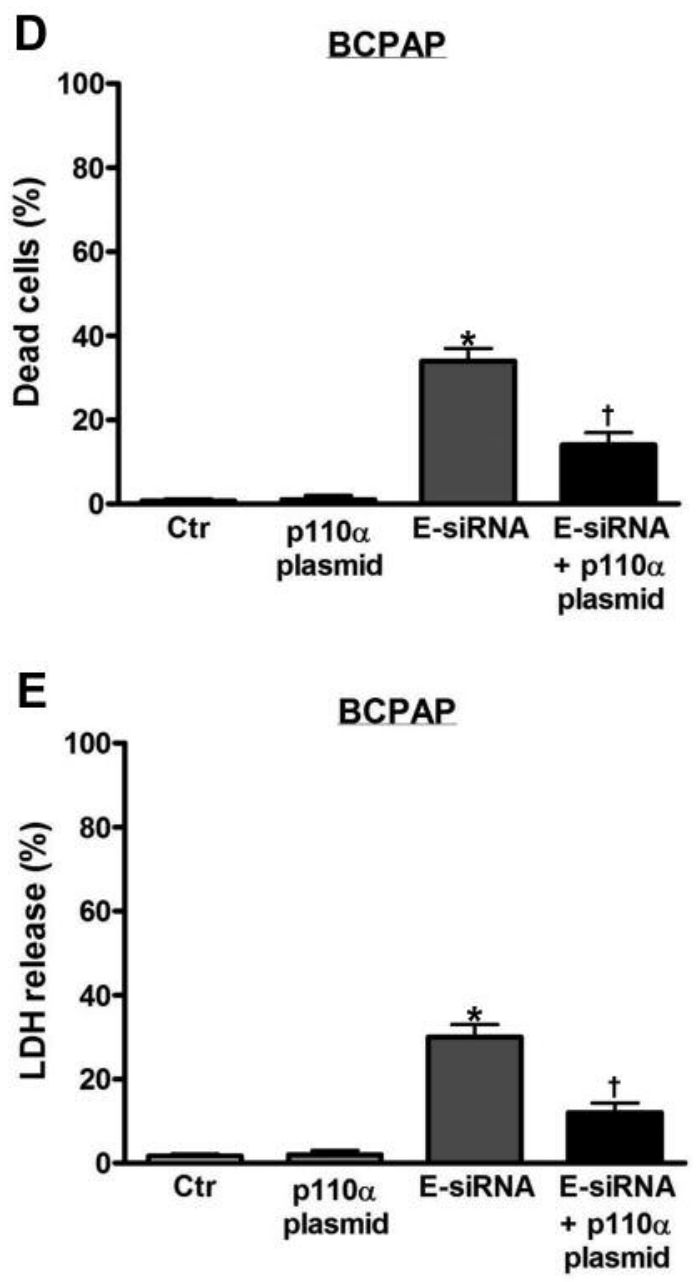
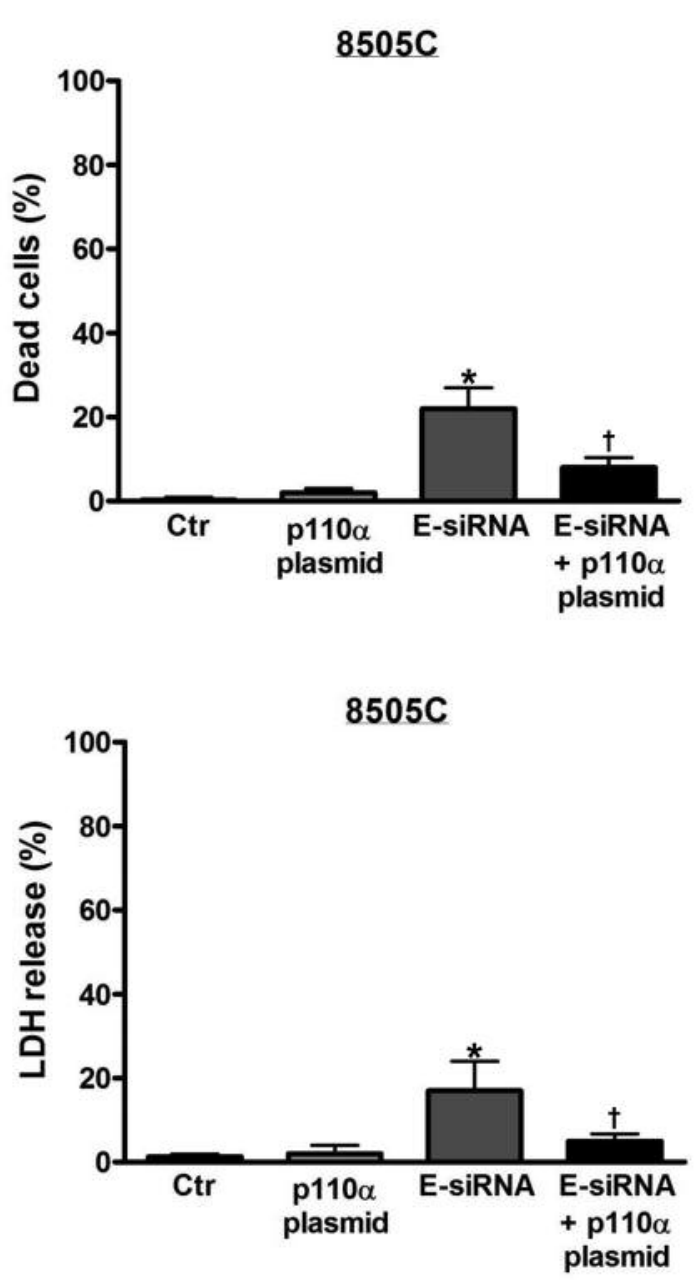

Figure 3. The involvement of phosphatidylinositol-3 kinase (PI3K)/AKT signaling in survival of enigma-deprived thyroid carcinoma cells. BCPAP and $8505 \mathrm{C}$ cells were transfected with p110 $\alpha$ plasmid prior to transfection of enigma siRNA (E-siRNA) for 48 h, and then the protein levels of total and phospho-AKT, survivin and cleaved poly (ADP-ribose) polymerase (PARP) were measured (A), and quantified by densitometry (B), and normalized to $\beta$-actin levels. Cell viability $(C)$, the percentage of dead cells $(D)$ and cytotoxic activity $(E)$ were also measured. All experiments were performed in triplicate. The blots are representative of independent experiments. Data are expressed as mean $\pm S . E . * p<0.05 v s$. control $(C t r)$; ${ }^{\dagger} p<0.05$ vs. cells transfected with E-siRNA alone. LDH: Lactate dehydrogenase; Scr: scramble RNA.

thyroid carcinoma cells (21-26). Although the PDZ-LIM family protein LMP-1 was shown to inhibit cell death by regulating PI3K/AKT signaling in nasal natural killer/T-cell lymphoma cells (11), the participation of PI3K/AKT signaling in pro-survival effect of enigma in thyroid carcinoma cells has not been evaluated before. In the present study, repression of enigma reduced total and phospho-AKT protein levels. Furthermore, activation of PI3K/AKT signaling with transfection of $\mathrm{p} 110 \alpha$ plasmid in enigma siRNA-transfected cells increased cell viability, and decreased the percentage of dead cells, cytotoxic activity and cleaved PARP protein levels. Collectively, our findings show that suppression of enigma inactivates PI3K/AKT signaling in thyroid carcinoma cells, and activation of PI3K/AKT signaling mitigates cell death in enigma-deprived thyroid carcinoma cells. In addition, these results denote that enigma is involved in cell survival via PI3K/AKT signaling in thyroid carcinoma cells. Further to this suggestion, our results may illuminate another pathway for PI3K/AKT signaling to enhance survival of thyroid carcinoma cells.

Survivin is a member of the inhibitor of apoptosis protein family, and is expressed ubiquitously in fetal tissues (27). Additionally, survivin is related to chemoresistance and unfavorable prognosis in patients with malignant tumors, and overexpression of survivin is relevant to dedifferentiation and progression in thyroid cancer $(19,28)$. In this respect, we 
A

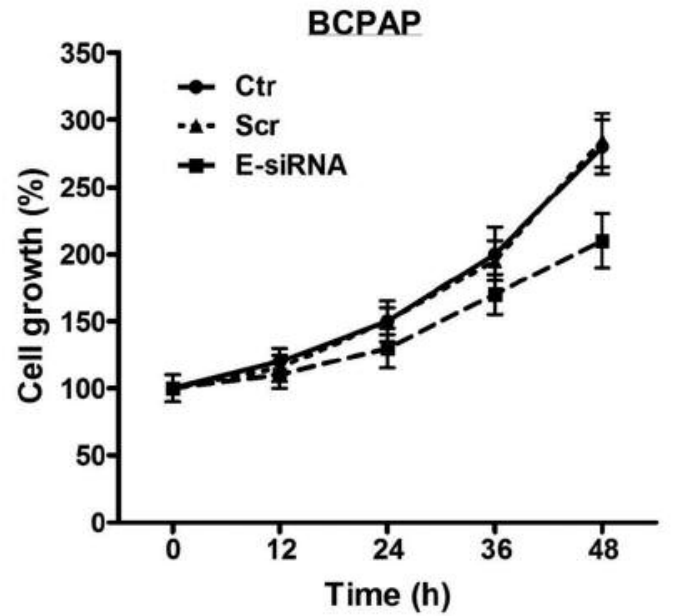

B
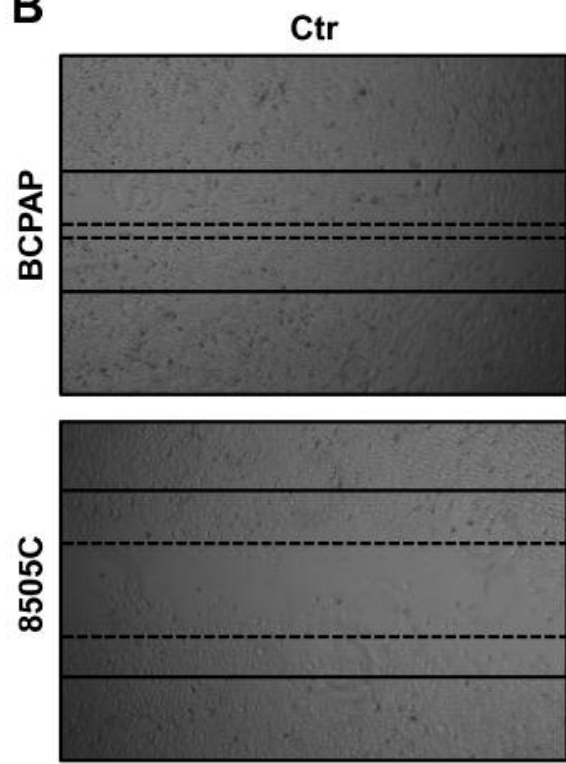

$500 \mu \mathrm{m}$

C

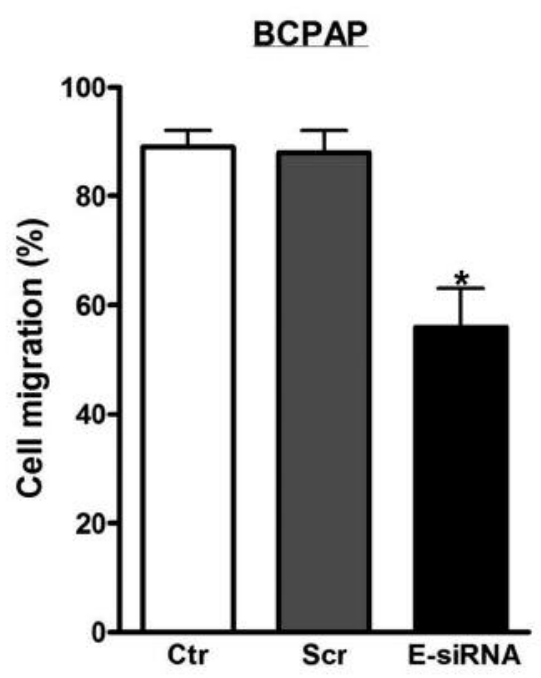

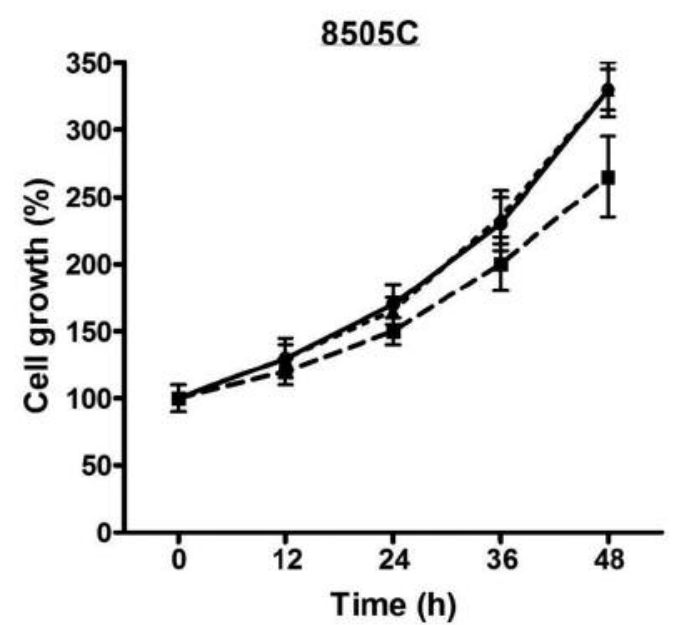

Scr

E-siRNA
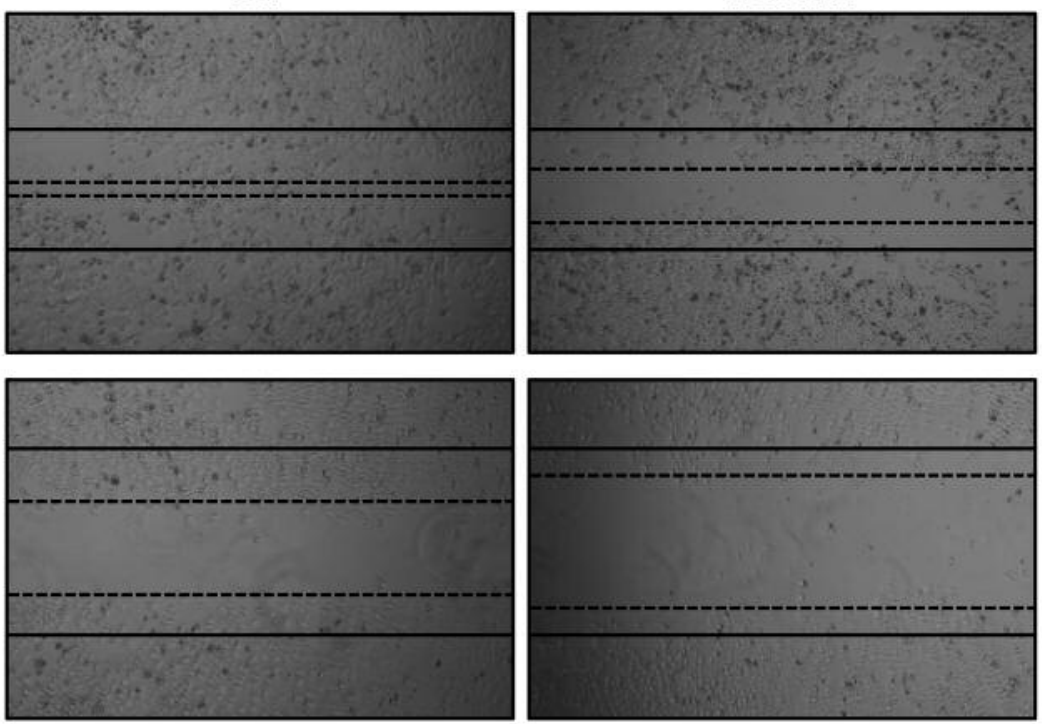

$8505 \mathrm{C}$

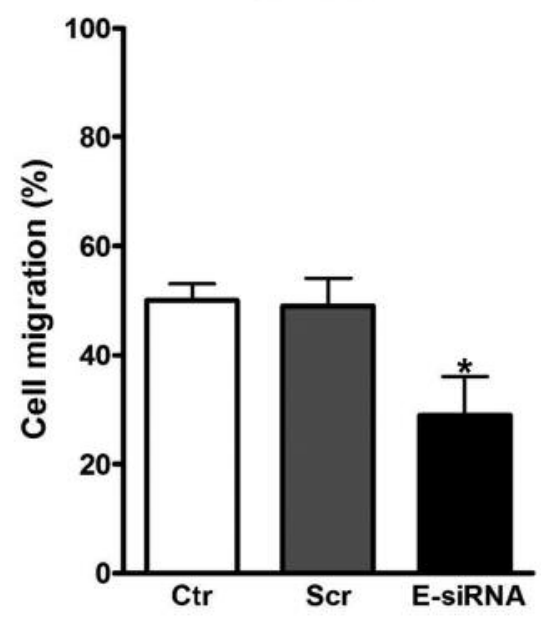

Figure 4. Continued 

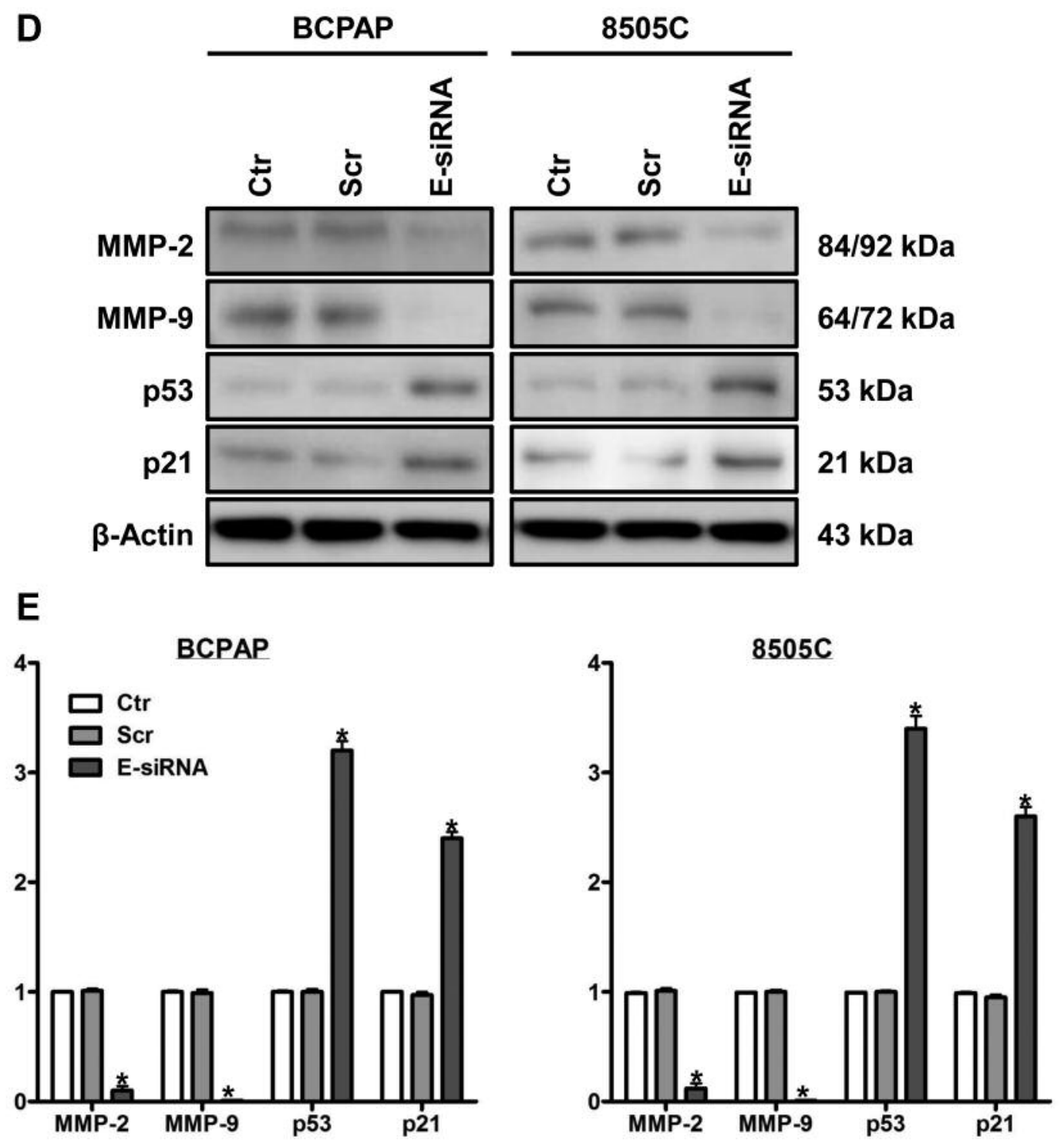

Figure 4. The role of enigma in proliferation and migration of thyroid carcinoma cells. A: BCPAP and 8505C cells were transfected with enigma siRNA (E-siRNA) for 12, 24, 36 and $48 \mathrm{~h}$, after which cell growth rate was measured. B and C: BCPAP and 8505C cells were transfected with E-siRNA for $48 \mathrm{~h}$, and then cell migration using wound-healing assay was measured. D and E: BCPAP and 8505C cells were transfected with E-siRNA for $48 \mathrm{~h}$. The protein levels of matrix metalloproteinase-2 (MMP-2), matrix metalloproteinase-9 (MMP-9), p53 and p21 were measured, and quantified by densitometry, and normalized to $\beta$-actin levels. All experiments were performed in triplicate. The blots are representative of independent experiments. Data are expressed as mean \pm S.E. ${ }^{*} p<0.05$ vs. control (Ctr). Scr: Scramble RNA.

reported that expression of survivin was associated with survival of thyroid carcinoma cells (21-26). Survivin is stimulated through PI3K/AKT signaling in response to cytokines, growth factors and chemotherapeutic agents in malignant cells (29). Regarding the interactions among the PDZ-LIM family protein, PI3K/AKT signaling and survivin, LMP-1 was implicated in augmentation of expression of survivin by activating PI3K/AKT signaling in nasal natural
killer/T-cell lymphoma animal model (11). However, the relationship among enigma, PI3K/AKT signaling and survivin in thyroid carcinoma cells has not been investigated. In the present study, inhibition of enigma decreased survivin protein levels, and activation of PI3K/AKT signaling in enigma siRNA-transfected cells diminished decrement of survivin protein levels. Intriguingly, these alterations were accompanied by increment of cell viability and decrement of 
the percentage of dead cells, cytotoxic activity and cleaved PARP protein levels. Taken together, our findings reveal that repression of enigma abrogates expression of survivin in thyroid carcinoma cells, and activation of PI3K/AKT signaling attenuates cell death with reexpression of survivin in enigma-inactivated thyroid carcinoma cells. Moreover, these results imply that enigma counteracts cell death via intensification of PI3K/AKT signaling and survivin in thyroid carcinoma cells. However, the detailed mechanism for the involvement of enigma in communicating with PI3K/AKT signaling and survivin should be further explored.

MMP-2, MMP-9, p53 and p21 are involved in proliferation, migration, invasion and metastasis of tumor cells (30-32). In thyroid cancer, our report shows that MMP-2, MMP-9, p53 and p21 were responsible for proliferation and migration of thyroid carcinoma cells (33). In terms of the influence of enigma on proliferation and migration, enigma was found to mediate mitogenic signaling of RET/PTC2 and to attenuate antiproliferative activity of p53 through MDM2 (7, 8, 14). In the present study, suppression of enigma reduced cell growth and migration with concomitant decrease of MMP-2 and MMP-9 protein levels and increase of p53 and p21 protein levels, indicating that inhibition of enigma ameliorates cell proliferation and migration through manipulation of MMP-2, MMP-9, p53 and p21 in thyroid carcinoma cells. These results show that enigma modulates proliferation and migration as well as survival of thyroid carcinoma cells. In clinical practice, these findings may highlight enigma protein as a potential drug target in thyroid cancer refractory to conventional therapy.

\section{Acknowledgements}

This work was supported by the National Research Foundation of Korea (NRF) grant funded by the Korea government (MSIP) (No. 2015R1A2A2A01003589) to S.J. Lee, Republic of Korea, and also was supported by Hallym University Research Fund to S.J. Lee, Republic of Korea.

\section{References}

1 Nervo A, Gallo M, Samà MT, Felicetti F, Alfano M, Migliore E, Marchisio F, Berardelli R, Arvat E and Piovesan A: Lenvatinib in advanced radioiodine-refractory thyroid cancer: a snapshot of real-life clinical practice. Anticancer Res 38: 1643-1649, 2018.

2 Haugen BR, Alexander EK, Bible KC, Doherty GM, Mandel SJ, Nikiforov YE, Pacini F, Randolph GW, Sawka AM, Schlumberger M, Schuff KG, Sherman SI, Sosa JA, Steward DL, Tuttle RM and Wartofsky L: 2015 American Thyroid Association management guidelines for adult patients with thyroid nodules and differentiated thyroid cancer. Thyroid 26: 1-133, 2016.

3 Krcmery J, Camarata T, Kulisz A and Simon H-G: Nucleocytoplasmic functions of the PDZ-LIM protein family: new insights into organ development. BioEssays 32: 100-108, 2010 .
4 Wu RY and Gill GN: LIM domain recognition of a tyrosinecontaining tight turn. J Biol Chem 269: 25085-25090, 1994.

5 Wu R, Durick K, Songyang Z, Cantley LC, Taylor SS and Gill GN: Specificity of LIM domain interactions with receptor tyrosine kinases. J Biol Chem 272: 15934-15941, 1996.

6 Barrès R, Gremeaux T, Gual P, Gonzalez T, Gugenheim J, Tran A, Le Marchand-Brustel Y and Tanti JF: Enigma interacts with adaptor protein with $\mathrm{PH}$ and $\mathrm{SH} 2$ domains to control insulininduced actin cytoskeleton remodeling and glucose transporter translocation. Mol Endocrinol 20: 2864-2875, 2006.

7 Borrello MG, Mercalli E, Perego C, Degl'Innocenti D, Ghizzoni S, Arigho E, Eroini B, Rizzetti MG and Pierotti MA: Differential interaction of enigma protein with the two RET isoforms. Biochem Biophys Res Commun 296: 515-522, 2002.

8 Durick K, Gill GN and Taylor SS: Shc and enigma are both required for mitogenic signaling by Ret/ptc2. Mol Cell Biol 18: 2298-2308, 1998.

9 Tamura N, Ohno K, Katayama T, Kanayama N and Sato K: The PDZ-LIM protein CLP36 is required for actin stress fiber formation and focal adhesion assembly in BeWo cells. Biochem Biophys Res Commun 364: 589-594, 2007.

10 Healy NC and O'Connor R: Sequestration of PDLIM2 in the cytoplasm of monocytic/macrophage cells is associated with adhesion and increased nuclear activity of NF-kappaB. J Leukoc Biol 85: 481-490, 2009.

11 Sun L, Zhao Y, Shi H, Ma C and Wei L: LMP-1 induces survivin expression to inhibit cell apoptosis through the NF-kB and PI3K/AKT signaling pathways in nasal NK/T-cell lymphoma. Oncol Rep 33: 2253-2260, 2015.

12 Guy PM, Kenny DA and Gill GN: The PDZ domain of the LIM protein enigma binds to beta-tropomyosin. Mol Biol Cell 10: 1973-1984, 1999.

13 Camarata T, Krcmery J, Snyder D, Park S, Topczewski J and Simon H-G: Pdlim7 (lmp4) regulation of Tbx5 specifies zebrafish heart atrio-ventricular boundary and valve formation. Dev Biol 337: 233-245, 2010.

14 Jung CR, Lim JH, Choi Y, Kim DG, Kang KJ, Noh SM and Im DS: Enigma negatively regulates p53 through MDM2 and promotes tumor cell survival in mice. J Clin Invest 120: 44934506, 2010.

15 Kales SC, Nau MM, Merchant AS and Lipkowitz S: Enigma prevents CBL-c-mediated ubiquitination and degradation of RETMEN2A. PLoS One 9: e87116, 2014.

16 Firek AA, Perez MC, Gonda A, Lei L, Munir I, Simental AA, Carr FE, Becerra BJ, De Leon M and Khan S: Pathologic significance of a novel oncoprotein in thyroid cancer progression. Head Neck 39: 2459-2469, 2017.

17 Xing M: Genetic alterations in the phosphatidylinositol-3 kinase/AKT pathway in thyroid cancer. Thyroid 20: 697-706, 2010.

18 Saji $M$ and Ringel MD: The PI3K-AKT-mTOR pathway in initiation and progression of thyroid tumors. Mol Cell Endocrinol 32: 20-28, 2010.

19 Pannone G, Santoro A, Pasguali D, Zamparese R, Mattoni M, Russo G, Landriscina M, Piscazzi A, Toti P, Cignarelli M, Lo Muzio L and Bufo P: The role of survivin in thyroid tumors: differences of expression in well-differentiated, non-welldifferentiated, and anaplastic thyroid cancers. Thyroid 24: 511$519,2014$.

20 Testa JR and Tsichlis PN: AKT signaling in normal and malignant cells. Oncogene 24: 7391-7393, 2005. 
21 Kim SH, Kang JG, Kim CS, Ihm S-H, Choi MG, Yoo HJ and Lee SJ: HSP70 inhibition potentiates radicicol-induced cell death in anaplastic thyroid carcinoma cells. Anticancer Res 34: 48294837, 2014.

22 Kim SH, Kang JG, Kim CS, Ihm S-H, Choi MG, Yoo HJ and Lee SJ: The effect of 17-allylamino-17-demethoxygeldanamycin alone or in combination with paclitaxel on anaplastic thyroid carcinoma cells. Endocrine 48: 886-893, 2015.

23 Kim SH, Kang JG, Kim CS, Ihm S-H, Choi MG, Yoo HJ and Lee SJ: The novel heat shock protein 90 inhibitor NVP-AUY 922 synergizes with the histone deacetylase inhibitor PXD101 in induction of death of anaplastic thyroid carcinoma cells. J Clin Endocrinol Metab 100: E253-E261, 2015.

24 Kim SH, Kang JG, Kim CS, Ihm S-H, Choi MG, Yoo HJ and Lee SJ: The heat shock protein 90 inhibitor SNX5422 has a synergistic activity with histone deacetylase inhibitors in induction of death of anaplastic thyroid carcinoma cells. Endocrine 51: 274-282, 2016.

25 Kim SH, Kang JG, Kim CS, Ihm S-H, Choi MG, Yoo HJ and Lee SJ: Synergistic cytotoxicity of BIIB021 with triptolide through suppression of PI3K/AKT/mTOR and NF-kB signal pathways in thyroid carcinoma cells. Biomed Pharmacother 83: 22-32, 2016

26 Kim SH, Kang JG, Kim CS, Ihm S-H, Choi MG, Yoo HJ and Lee SJ: Gemigliptin, a novel dipeptidyl peptidase-IV inhibitor, exerts a synergistic cytotoxicity with the histone deacetylase inhibitor PXD101 in thyroid carcinoma cells. J Endocrinol Invest, 41:677-689, 2018.
27 Salvesen GS and Duckett CS: IAP proteins: blocking the road to death's door. Nat Rev Mol Cell Biol 3: 401-410, 2002.

28 Mita AC, Mita MM, Nawrocki ST and Giles FJ: Survivin: key regulator of mitosis and apoptosis and novel target for cancer therapeutics. Clin Cancer Res 14: 5000-5005, 2008.

29 Zhao P, Meng Q, Liu LZ, You YP, Liu N and Jiang BH: Regulation of survivin by PI3K/AKT/p70S6K1 pathway. Biochem Biophys Res Commun 395: 219-24, 2010.

30 Roomi MW, Monterrey JC, Kalinovsky T, Rath $M$ and Niedzwiecki A: Patterns of MMP-2 and MMP-9 expression in human cancer cell lines. Oncol Rep 21: 1323-1333, 2009.

31 Pietsch EC, Sykes SM, McMahon SB and Murphy ME: The p53 family and programmed cell death. Oncogene 27: 6507-6521, 2008.

32 Abbas T and Dutta A: p21 in cancer: intricate networks and multiple activities. Nat Rev Cancer 9: 400-414, 2009.

$33 \mathrm{Kim}$ SH, Kang JG, Kim CS, Ihm S-H, Choi MG, Yoo HJ and Lee SJ: Synergistic cytotoxicity of the dipeptidyl peptidase-IV inhibitor gemigliptin with metformin in thyroid carcinoma cells. Endocrine 59: 383-394, 2018.
Received April 5, 2018

Revised May 13, 2018

Accepted May 15, 2018 